\title{
New records of Nasitrema atenuatta and Nasitrema globicephalae (Trematoda: Brachycladiidae) Neiland, Rice and Holden, 1970 in delphinids from South Atlantic
}

\author{
Mariana Bertholdi Ebert ${ }^{1^{*}}$ and Ana Luisa Schifino Valente ${ }^{2}$ \\ 1 Instituto de Pesquisas Cananéia. Rua Tristão Lobo, 199. CEP 11990-000. Cananéia, SP, Brazil . \\ 2 Universidade Federal de Pelotas, Instituto de Biologia, Departamento de Morfologia. Campus Capão do Leão - IB, Prédio 20. CEP 96010-900. \\ Pelotas, RS, Brazil . \\ *Corresponding author. E-mail: mbe.bio@gmail.com
}

\begin{abstract}
Twenty one Sotalia guianensis (van Bénéden, 1864) and one Steno bredanensis (Lesson, 1828) stranded on Brazilian coast were necropsied. Two species of Nasitrema (Trematoda: Brachycladiidae) Ozaki, 1935, were identified in the respiratory tract of the dolphins. Nasitrema atenuatta (Neiland, Rice and Holden, 1970 ) was found in S. guianensis (prevalence $28.7 \%$, mean intensity 4.66 and mean abundance 1.33 ) and $S$. bredanensis (mean intensity and mean abundance six helminths). Nasitrema globicephalae (Neiland, Rice and Holden, 1970) was only found in S. bredanensis, with an infection intensity of 14 helminths. Nasitrema atenuatta and $N$. globicephalae are reported for the first time in South Atlantic.
\end{abstract}

Helminths are the most diverse group of metazoan parasites of vertebrates, and are recognized as an important component of global biodiversity (Poulin and Morand 2004). Efforts directed to recording parasites species of cetaceans have increased in recent years, however, on the Brazilian coast, there are few studies concerning helminths infecting other organs besides the gastrointestinal tract (Santos et al. 1996; Marigo et al. 2010).

Trematodes of the genus Nasitrema infect the nasal cavity, the respiratory tract and nervous system of a wide variety of small odontocetes (Neiland et al. 1970; Dailey and Ridgway 1976; Forrester et al. 1980; Brieva and Oporto 1991; Dailey 2001), and can be related to individuals or mass strandings of these animals (Dailey 2001). Some studies indicate Nasitrema as the cause of eighth cranial neuropathy in Risso dolphins, Grampus griseus (Cuvier, 1812), in Japan (Morimitsu et al. 1992), cerebral necrosis in a common dolphin, Delphinus delphis Linnaeus, 1758, in California (Dailey and Walker 1978), encephalitis in striped dolphin, Stenella coeruleoalba (Meyen, 1833), and sinusitis and meningocefalites in four species of dolphins in the North Atlantic (O' Shea et al. 1991; Degollada et al. 2002). The lesions resulting from infections by these parasites can cause loss of balance and interfere with the echolocation, which can induce the stranding or even the death of the animal (Dailey 2005).

On the Brazilian coast, non-identified species of the genus Nasitrema has been reported parasitizing the central nervous system of Risso dolphins, G. griseus (MaiaNogueira 2000), the nasal cavity of bottlenose dolphins, Tursiops truncatus (Montagu, 1821), and the nasal cavity of estuarine dolphins, S. guianensis (Di Beneditto and Ramos 2004; Melo et al. 2006). None of these studies have mentioned the species identification.
Twenty-one specimens of the estuarine dolphin, $S$. guianensis, and a rough-toothed dolphin, S. bredanensis, found stranded on the beaches of Ilha Comprida, São Paulo state, Brazil (2451'00" S, 4740'00' W) between January 2011 and July 2012 were necropsied and flukes were collected from nasal cavities and lungs. Identification of cetacean species, biometry, and evaluation of decomposition stage of the carcasses followed Jefferson et al. (1993), IBAMA (2005) and Geraci and Lounsbury (2005). To collect the parasites, the dolphins' head were disjointed from the body and the nasal air sacs and sinuses were washed with water on a sieve (mesh $150 \mathrm{~mm}$ ). The bronchi and lungs of the animals were sectioned and opened, respectively, and washed on the sieve. All trematodes collected were washed in distillated water and fixed in $70 \%$ ethanol. Subsequently, for each dolphin, samples of the best preserved worms were separated, stained with Semichon carmine or Delafield hematoxylin, clarified in beech creosote, measured and mounted on permanent slides according to Amato et al. (1991). The identification of the trematodes followed specific literature (Neiland et al. 1970; Walker et al. 1984; Gibson, 2005). Parasitological indices such as prevalence, mean intensity of infection and mean abundance were calculated according to Bush et al. (1997).

The analyzed specimens of $S$. guianensis were mostly adults (mean length $=173.00 \pm 25.68 \mathrm{~cm}$ ) and were in stage two or three of decomposition (Geraci and Lounsbury 2005). A total of twenty-eight specimens of the trematode $N$. atenuatta (Figure 1) were recovered in these dolphins. In two dolphins, trematodes were found parasitizing the nasal air sacs and sinuses, while in other four individuals they were collected from the bronchi and lungs. All parasites were in mature stage and producing eggs. Morphological measurements of trematodes and parasitological indices 
are presented in Table 1. Few descriptions of Nasitrema species are known. Neiland et al. (1970) and Walker et al. (1984) presented comparative studies including size and some morphologic characters, where $N$. atenuatta is described with very bluntly lobed testes positioned on the first fifth or first sixth part of the body, ovary consisting of two or four blunt lobes and vitellaria beginning at anterior limits of anterior testis, whereas $N$. globicephalae is described with dendritic testes positioned on the second

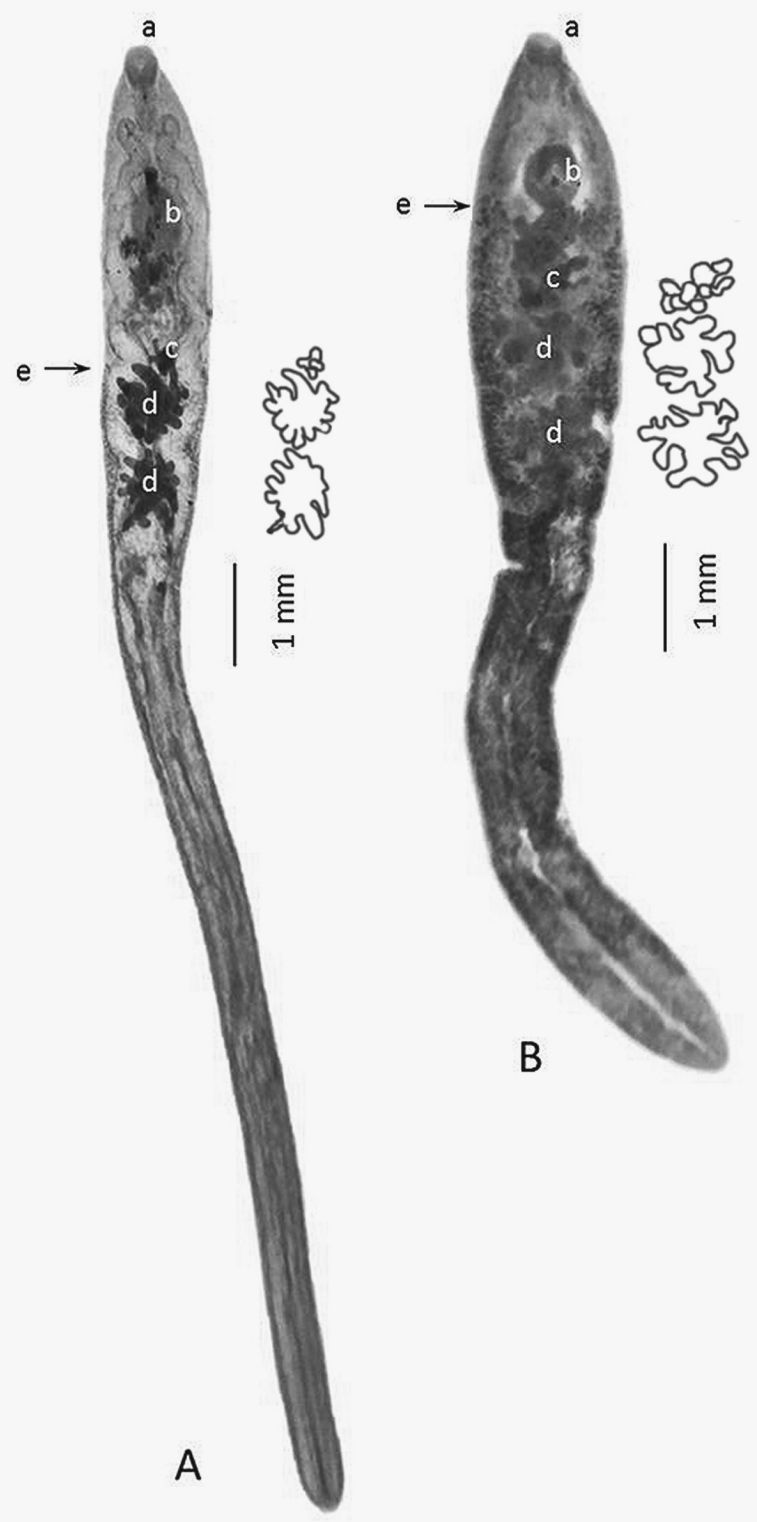

FIGURE 1. General view of Nasitrema atenuatta (A) and Nasitrema globicephalae (B) collected from Sotalia guianensis and Steno bredanensis, respectively, from South Atlantic. a. Oral sucker, b. Acetabulum, c. Ovary, d. Testes and e. Anterior limit of vitellaria distribution. Note very bluntly lobed testes positioned on the first fifth or first sixth of the body in A and dendritic testes positioned on the second quarter of the body in B. Ovary from $N$. globicephalae with more than five lobes. Testes and ovaries' drawings are reproduced beside the image. quarter of the body, ovary consisting of five to 10 short and blunt lobes and vitellaria beginning in a zone extending from midway between ovary and acetabulum to equator of acetabulum. These morphologic differences were used in this study to distinguish the species (Figure 1 and 2). $N$. atenuatta was longer and slender than $N$. globicephalae and the difference in the distribution of vitellaria and testes were notable (Figure 1). Testes in N. globicephalae were pediculate with ramified (bifurcated) extremities (Figure 2A) whereas in N. atenuatta they had many fingerlike lobes (Figure 2B). Nasitrema atenuatta has been found parasitizing the nasal air sacs of $S$. guianensis captured in Barranquila, Colombia (Bossenecker 1978). In Brazil, non-identified species of the genus Nasitrema have been reported as parasite of $S$. guianensis, in the state of Rio de Janeiro (Di Beneditto and Ramos 2004; Melo et al. 2006). This is the first record of Nasitrema atenuatta parasitizing Sotalia guianensis in the South Atlantic.

The only Steno bredanensis specimen analyzed was an adult female (269 cm length), which was found stranded alive. Cause of death was not identified. Necropsy was performed 12 hours after natural death. Forty-five adult flukes were recovered from the nasal air sacs and sinuses. Twenty were stained and prepared to identification. The species $N$. atenuatta $(\mathrm{n}=6)$ and $N$. globicephalae $(\mathrm{n}=$ 14) (Figure 1) were identified. Morphological data and parasitological indices are presented in the Table 1. Eggs of unidentified species of genus Nasitrema have been reported in the air sinuses from this dolphin species in the Canary Islands, North-Eastern Atlantic (Degollada et al. 2002). This is the first record of $N$. atenuatta and $N$. globicephalae parasitizing S. bredanensis.

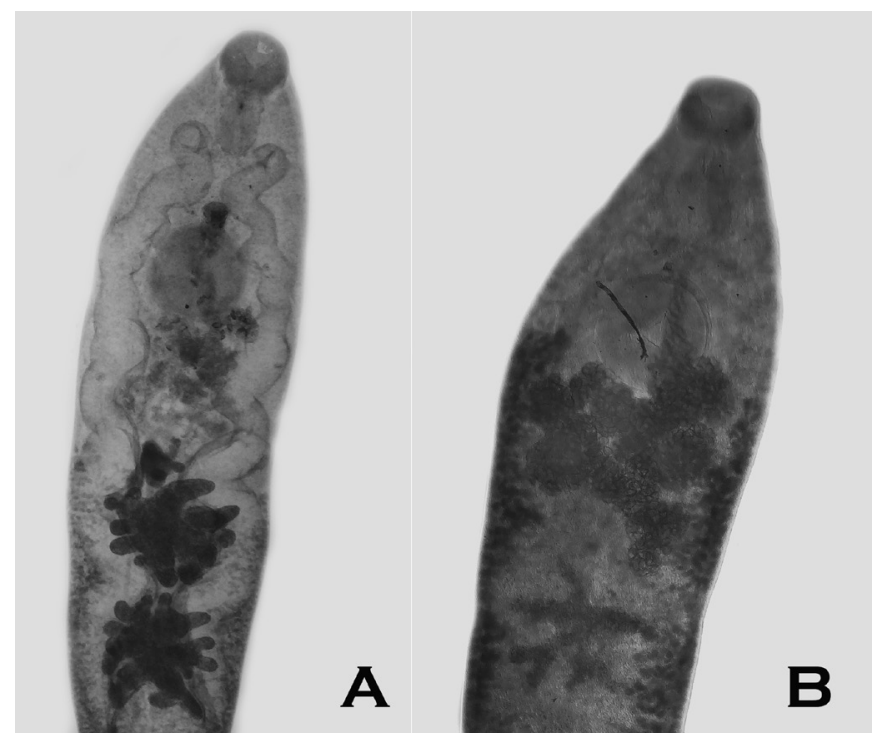

FIGURE 2. Nasitrema atenuatta (A): ovary with few lobes (4, two of them superimposed) and testes with lobes no dendritic. Nasitrema globicephalae (B): Dendritic testis. 
TABLE 1. Morphologic measurements and parasitological indices of Nasitrema atenuatta and N. globicephalae found in delphinids species from South Atlantic. Minimum, maximum and mean values (between parentheses) are presented.

\begin{tabular}{|c|c|c|c|}
\hline \multirow{3}{*}{$\begin{array}{l}\text { Parasites species and } \\
\text { morphologic measurements }\end{array}$} & \multicolumn{3}{|c|}{ Delphinids species } \\
\hline & \multirow{2}{*}{$\begin{array}{l}\text { Sotalia guianensis } \\
\text { N. atenuatta }\end{array}$} & \multicolumn{2}{|c|}{ Steno bredanensis } \\
\hline & & N. atenuatta & N. globicephalae \\
\hline Body length & 15.3-17.1 mm (16.1) & $14.5-16.8 \mathrm{~mm}(15.6)$ & $10.0-13.5 \mathrm{~mm}(12.1)$ \\
\hline Body width & $1.5-1.8 \mathrm{~mm}(1.6)$ & $1.0-1.8 \mathrm{~mm}(1.5)$ & $2.2-1.2 \mathrm{~mm}(1.7)$ \\
\hline Oral sucker length & $0.41-0.47 \mathrm{~mm}(0.43)$ & $0.41-0.45 \mathrm{~mm}(0.42)$ & $0.37-0.52 \mathrm{~mm}(0.44)$ \\
\hline Oral sucker width & $0.41-0.52 \mathrm{~mm}(0.46)$ & $0.33-0.49 \mathrm{~mm}(0.42)$ & $0.38-0.55 \mathrm{~mm}(0.46)$ \\
\hline Acetabulum length & $0.75-0.76 \mathrm{~mm}(0.75)$ & $0.59-0.74 \mathrm{~mm}(0.68)$ & $0.56-0.78 \mathrm{~mm}(0.66)$ \\
\hline Acetabulum width & $0.70-0.82 \mathrm{~mm}(0.74)$ & $0.56-0.76 \mathrm{~mm}(0.68)$ & $0.54-0.79 \mathrm{~mm}(0.67)$ \\
\hline Egg length & $0.05-0.09 \mathrm{~mm}(0.07)$ & 0.07-0.09 mm (0.07) & 0.07-0.09 mm (0.07) \\
\hline Egg width & $0.02-0.05 \mathrm{~mm}(0.04)$ & $0.04-0.05 \mathrm{~mm}(0.04)$ & 0.04-0.05 mm (0.04) \\
\hline Testes & lobed & lobed & dendritic \\
\hline Ovary & 2-4 lobes & 2-4 lobes & 5-8 lobes \\
\hline Vitellaria distribution & postacetabular & postacetabular & acetabular \\
\hline \multicolumn{4}{|l|}{ Parasitological indices } \\
\hline Prevalence (\%) & $28.57(6 / 21)$ & $100(1 / 1)$ & $100(1 / 1)$ \\
\hline Mean intensity & $4,66(28 / 6)$ & $6(6 / 1)$ & $14(14 / 1)$ \\
\hline Mean abundance & $1,33(28 / 21)$ & $6(6 / 1)$ & $14(14 / 1)$ \\
\hline
\end{tabular}

ACKNOWLEDGMents: The authors would like to thank PETROBRAS for the sponsorship through the program Petrobras Ambiental, Instituto de Pesquisas Cananéia and ICMBio-Iguape for logistic support, Projeto BotoCinza team for helping with the carcasses and necropsies, and J.M. for reviewing the manuscript.

\section{Literature Cited}

Amato, J.F.R., W.A. Boerger and S.B. Amato. 1991. Protocolos para Laboratório - Coleta e Processamento de Parasitos de Pescado. Rio de Janeiro: Imprensa Universitária, Universidade Rural do Rio de Janeiro. 81 p.

Bossenecker, P. J. 1978. The capture and care of Sotalia guianensis. Aquatic Mammals Journal 6: 13-17.

Brieva, L.M. and J.A. Oporto. 1991. Prevalencia e intensidad de la infección por tremátodos del género Nasitrema en el delfín chileno Cephalorhynchus eutropia (Cetacea: Delphinidae). Archivos de Medicina Veterinaria 23: 97-100.

Bush, A.O., K.D. Lafferty, J.M. Lotz, and A.W. Shostak. 1997. Parasitology Meets Ecology on Its Own Terms: Margolis et al. Revisited. The Journal of Parasitology 83: 575-583.

Dailey, M.D. 2001. Parasitic Diseases; p. 357-379 In L.A. Dierauf and. F.M.D. Gulland, (ed.). CRC Handbook of Marine Mammal Medicine. Boca Raton: CRC Press.

Dailey, M.D. 2005. Parasites of Marine Mammals; p. 408- 414 In K. Rohde (ed.). Marine Parasitology. Victoria: CSIRO Publishing.

Dailey, M. and S. Ridgway. 1976. A trematode from the round window of an Atlantic Bottlenosed dolphin's ear. Journal of Wildlife Diseases 12: 45-47.

Dailey, M.D. and W.A. Walker. 1978. Parasitism as a Factor (?) in Single Strandings of Southern California Cetaceans. The Journal of Parasitology 64: 593-596.

Degollada, E., M. Andre, M. Arbelo, and A. Fernandez. 2002. Incidence, pathology and involvement of Nasitrema species in odontocete strandings in the Canary Islands. Veterinary Record 150: 81-82.

Di Beneditto, A.P.M. and R.M.A. Ramos. 2004. Biology of the marine tucuxi dolphin (Sotalia fluviatilis) in south-eastern Brazil. Journal of the Marine Biological Association of the United Kingdom 84: 1245-1250.

Forrester, D.J., D.K. Odell, N.P. Thompson and J.R. White. 1980. Morphometrics, Parasites, and Chlorinated Hydrocarbon Residues of Pygmy Killer Whales from Florida. Journal of Mammalogy 61: 356360.

Geraci, J.R. and V.J. Lounsbury. 2005. Marine Mammals Ashore: A Field Guide for Strandings. Second Edition. Baltimore: National Aquarium in Baltimore. 371 p.

Gibson, D.I. 2005. Family Brachycladiidae Odhner, 1905; p. 641-652 In D.I. Gibson, A. Jones and R.A. Bray (ed.). Keys to the Trematoda. London: CABI Publishing.
IBAMA. 2005. Protocolo de conduta para encalhes de mamíferos aquáticos: Rede de encalhes de mamíferos aquáticos do Nordeste. Recife: Edições IBAMA. 298 p.

Jefferson, T.A., S. Leatherwood, and M.A. Webber. 1993. FAO species identification guide. Marine mammals of the world. Rome: FAO. 320 p.

Maia-Nogueira, R. 2000. Primeiro registro de golfinho-de-Risso (Grampus griseus) G. Cuvier, 1812 (Cetacea, Delphinidae), no litoral do estado da Bahia, incluindo uma revisão da espécie em águas brasileiras. Bioikos 14: 34-43.

Marigo, J., V. Ruoppolo, F.C.W. Rosas, A.L.S. Valente, M.R. Oliveira, R.A. Dias and J.L. Catão-Dias. 2010. Helminths of Sotalia guianensis (Cetacea: Delphinidae) from the South and Southeastern Coasts of Brazil. Journal of Wildlife Diseases 46: 599-602.

Melo, O.P., R.M.A. Ramos and A.P.M. Di Beneditto. 2006. Helminths of the marine tucuxi, Sotalia fluviatilis (Gervais, 1853) (Cetacea: Delphinidae), in northern Rio de Janeiro State, Brazil. Brazilian Archives of Biology and Technology 49: 145-148.

Morimitsu, T., H. Kawano, K. Torihara, E. Kato, and M. Koono. 1992. Histopathology of eighth cranial nerve of mass stranded dolphins at Goto Islands, Japan. Journal of Wildlife Diseases 28: 656-658.

Neiland, K.A., D. W. Rice and B.L. Holden. 1970. Helminths of Marine Mammals, I. The Genus Nasitrema, Air Sinus Flukes of Delphinid Cetacea. Journal of Parasitology 56: 305-316.

O'Shea, T.J., B.L. Homer, E.C. Greiner and A.W. Layton. 1991. Nasitrema sp.associated encephalitis in a striped dolphin (Stenella coeruleoalba) stranded in the Gulf of Mexico. Journal of Wildlife Diseases 27: 706709.

Poulin, R. and S. Morand. 2004. Parasite Biodiversity. Washington D.C.: Smithsonian Institution Books 216 p.

Santos, C.P., K. Rohde, R. Ramos, A.P. di Beneditto and L. Capistrano. 1996. Helminths of cetaceans on the Southeastern Coast of Brazil. Journal of the Helminthological Society of Washington 63: 149-152.

Walker, W.A., F.G. Hochberg and E.S. Hacker. 1984. The potential use of the parasites Crassicauda (Nematoda) and Nasitrema (Platyhelminthes) as biological tags and their role in the natural mortality of Common dolphins, Delphinus delphis, in the eastern north Pacific. NOAA, NMFS, SFC-Administrative Report LJ-84-08C.

RECEIVED: April 2013

ACCEPTED: October 2013

Published ONLINE: November 2013

EdITORIAL RESPONSIBILITY: Simone Chinicz Cohen 